\title{
Dynamic Model-Free and Model-Fitting Kinetic Analysis during Torrefaction of Oil Palm Frond Pellets
}

\author{
Sharmeela Matali*, Norazah Abd Rahman, Siti Shawalliah Idris, Nurhafizah Yaacob
}

Faculty of Chemical Engineering, Universiti Teknologi MARA, 40450 Shah Alam, Selangor, Malaysia.

Received: $2^{\text {nd }}$ January 2020; Revised: 29th January 2020; Accepted: 29th January 2020;

Available online: 28th February 2020; Published regularly: April 2020

\begin{abstract}
Torrefaction is a thermal conversion method extensively used for improving the properties of biomass. Usually this process is conducted within a temperature range of $200-300{ }^{\circ} \mathrm{C}$ under an inert atmosphere with residence time up to 60 minutes. This work aimed to study the kinetic of thermal degradation of oil palm frond pellet (OPFP) as solid biofuel for bioenergy production. The kinetics of OPFP during torrefaction was studied using frequently used iso-conversional model fitting (Coats-Redfern (CR)) and integral model-free (Kissinger-Akahira-Sunose (KAS)) methods in order to provide effective apparent activation energy as a function of conversion. The thermal degradation experiments were conducted at four heating rates of $5,10,15$, and $20^{\circ} \mathrm{C} / \mathrm{min}$ in a thermogravimetric analyzer (TGA) under nonoxidative atmosphere. The results revealed that thermal decomposition kinetics of OPFP during torrefaction is significantly influenced by the severity of torrefaction temperature. Via Coats-Redfern method, torrefaction degradation reaction mechanism follows that of reaction order with $n=1$. The activation energy values were $239.03 \mathrm{~kJ} / \mathrm{mol}$ and $109.28 \mathrm{~kJ} / \mathrm{mol}$ based on KAS and CR models, respectively. Copyright $\odot 2020$ BCREC Group. All rights reserved
\end{abstract}

Keywords: Torrefaction; Oil palm frond; Kinetic parameters; Biomass; Bioenergy

How to Cite: Matali, S., Rahman, N.A., Idris, S.S., Yaacob, N. (2020). Dynamic Model-Free and ModelFitting Kinetic Analysis during Torrefaction of Oil Palm Frond Pellets. Bulletin of Chemical Reaction Engineering \& Catalysis, 15(1), 253-263 (doi:10.9767/bcrec.15.1.6985.253-263)

Permalink/DOI: https://doi.org/10.9767/bcrec.15.1.6985.253-263

\section{Introduction}

Malaysia has been committed to diversify its fuel source where policies on fuel diversification were first introduced in 1999 to promote renewable energy (RE) usage. Malaysia is blessed with indigenous generation mix of renewable energy resources such as biomass and biomass materials (oil palm mill/plantation residues, forestry biomass, agro-based and farming industries biomass waste), mini-hydro power, solar power and wind energy [1]. In relation to future energy demand and fossil fuel depleting re-

* Corresponding Author.

E-mail: sharmeela@uitm.edu.my (S. Matali);

Telp: +60-13-2990609, Fax: +60-3-55436300 serves, biomass has been identified as one of the viable renewable energy sources and is gaining importance for possible utilization as co-fuel, particularly in coal-fired power plant. According to Ozturk et al. [2], Malaysia produces approximately 168 million tons of biomass yearly, which includes timber, oil palm waste, rice husks, coconut trunk fibers, municipal, and sugarcane wastes. As for electricity generation from renewable sources, based on Peninsular Malaysia Electricity Supply Outlook 2017 report [3], Peninsular Malaysia has a total licensed generated capacity of $392 \mathrm{MW}$, with $89 \mathrm{MW}$ (23\%) of generation capacity from locally sourced biomass, second to solar photovoltaic (PV) of 235 MW (60\%), followed by biogas of 34 MW (9\%) and mini hydro of $34 \mathrm{MW}(8 \%)$. Renewable ener- 
gy from biomass source is regarded as a shortterm and sustainable energy resource with mature and readily applicable conversion technologies and could be used in the form of solid, liquid and gaseous products [10].

Biomass is considered carbon-neutral because it releases about the same amount of carbon dioxide as fossil fuels but the net amount of carbon dioxide remains at zero since the growth of new plants reduces the carbon dioxide in the atmosphere via photosynthesis [6]. Malaysia is one of the world's largest producer of crude palm oil that generates massive amount of waste both from plantation and mill processing activities. From total biomass waste generation, palm oil industry, which covers 5.4 million hectares of oil palm plantation, contributes more than $90 \%$ of total biomass waste generation in Malaysia. Currently, biomass power plants utilising oil palm waste mainly focused on mill waste i.e. empty fruit bunch (EFB) and palm oil mill effluent (POME). At present, there are eight oil palm waste-based power plants in Malaysia and connected to the grid. Six are based on EFB whereas remaining two utilise POME as their fuel. However, among all types of oil palm biomass waste, oil palm frond (OPF) is the highest contributor where for every hectare of an oil palm plantation, around 10 tonnes of dry palm fronds are produced. OPF has high potential as bioenergy source as it possesses the highest energy among total oil palm waste [7].

Biomass in raw form has its limitations such as high moisture content, low bulk and energy densities, hygroscopic behavior and poor grindability, which makes it substantial for biomass to undertake thermal pre-treatment process. Torrefaction, also known as slow pyrolysis, is able to upgrade biomass properties where torrefied solid products are mainly characterized on its upgraded quality, i.e. increased energy density, hydrophobicity, increased brittleness thus improved grindability, microbial and biodegradation resistance, and low bulk density. Understanding of kinetic parameters such as activation energy, pre-exponential factor and reaction mechanism of biomass thermal degradation, where in this case, during limited torrefaction temperature range $\left(200-300^{\circ} \mathrm{C}\right)$, is also in need for torrefaction reactor design and optimization of thermochemical process conditions [8]. To date, oil palm frond characteristics when subjected to torrefaction has not been documented intensively, particularly in densified form. Therefore, the objectives of this study focus on oil palm fronds properties in terms of fuel characteristics, thermal degradation be- havior and kinetic analysis during torrefaction. The findings from this study is deemed important in order to produce compatible and viable solid bioenergy feedstock.

\section{Materials and Methods}

\subsection{Torrefaction Experiments}

Oil palm frond (OPF) samples were collected from private-owned plantation in Klang province, Selangor, Malaysia. Bulky OPF were chipped and crushed into small particle sizes of approximately $5 \mathrm{~mm}$. Prior to densification, the samples were then dried to achieve moisture content less than $12 \mathrm{wt} \%$. Pelletization was done in Forest Research Institute of Malaysia (FRIM) using pellet machine with a cylindrical die opening of $6 \mathrm{~mm}$ in diameter and the length of produced pellets ranged from 1 to 6 $\mathrm{cm}$. Torrefaction experiments were performed by heating $20 \mathrm{~g}$ of raw OPF pellets placed in a crucible and positioned in the middle of each zone of horizontal tube furnace OTF-1200X (MTI Corporation, USA) as shown in Figure 1. To ensure inert condition was achieved in the furnace, nitrogen gas was flowed continuously for 15 minutes at $1 \mathrm{~L} / \mathrm{min}$. The torrefaction process was carried out at fixed slow heating rate of $10{ }^{\circ} \mathrm{C} / \mathrm{min}$ from ambient to target temperatures of $200{ }^{\circ} \mathrm{C}, 250{ }^{\circ} \mathrm{C}$, and $300{ }^{\circ} \mathrm{C}$ and upon reaching these values, the heating was held for duration of 60 minutes. Pellet chars collected were weighed and stored in airtight containers and for further use, the samples would again be dried at $105^{\circ} \mathrm{C}$ for 24 hours.

\subsection{Characterization of Raw and Torrefied OPFP Samples}

Proximate and elemental analyses were carried out using Thermo Finnigan Flashed 1112 analyzer and thermo balance TGA/SDRA51 ${ }^{e}$ (Mettler Toledo), respectively, and followed the procedures of ASTM International E113108(2014) and ASTM International D5373-16. High heating values (HHV) of raw and torrefied OPF pellets were determined using a bomb calorimeter (IKA-works C5000) in accordance to ASTM International D5865-13. All results collected were based on duplicate tests and repetitions were done if inconsistency data was observed.

Thermal decomposition during torrefaction of pellet samples were achieved using a thermogravimetric analyzer, TGA/SDRA51 ${ }^{\mathrm{e}}$ (Mettler Toledo, USA) using nitrogen gas at atmospheric pressure with constant flow-rate of $50 \mathrm{~mL} / \mathrm{min}$. To provide inert environment and 
preventing secondary volatiles release, nitrogen gas was purged for 15 minutes. For each test, pellet sample size of $5 \mathrm{mg}$ was placed in a $70 \mu \mathrm{L}$ alumina crucible. TGA's furnace temperature was raised from 25 to $105^{\circ} \mathrm{C}$ and heating was held at this temperature for 5 minutes to ensure complete removal of surface moisture and this temperature was also selected to be the basis of kinetic analysis [9]. To achieve complete thermal degradation, the heating was continued up to temperature $800{ }^{\circ} \mathrm{C}$.

\subsection{Torrefaction Kinetics of Raw OPFP}

For torrefaction kinetic analysis, samples were heated at four dynamic heating rates of 5 , 10,15 and $20^{\circ} \mathrm{C} / \mathrm{min}$. In this study, single-step reaction scheme was implemented according to Equation (1) [10]:

$$
\text { Solid Biomass } \stackrel{k}{\longrightarrow} \text { Char }+ \text { Volatiles }
$$

where $k$ is the global apparent rate constant and dependent on temperature as described in Arrhenius Law and is shown in Equation (2):

$$
k(T)=A \exp \left(\frac{-E_{a}}{R T}\right)
$$

where $A$ is the pre-exponential factor $\left(\mathrm{min}^{-1}\right)$, $E_{a}$ is the apparent activation energy $(\mathrm{kJ} / \mathrm{mol}), R$ is the universal gas constant $(8.314 \mathrm{~J} / \mathrm{mol} \cdot \mathrm{K})$, and $T$ is the temperature (in K). For single step solid-state reaction, the differential equation under isothermal conditions can be expressed as Equation (3):

$$
\frac{d \alpha}{d t}=k(T) \cdot f(\alpha)
$$

where $d \alpha / d t$ is the rate of conversion $(\alpha)$ with time $(t)$, and $f(\alpha)$ is the reaction model. Conversion, $\alpha$ can be defined as in Equation (4):

$$
\alpha=\frac{m_{0}-m_{t}}{m_{0}-m_{f}}
$$

where $m_{o}$ is the initial sample weight, $m_{t}$ is the sample weight at time $t$, and $m_{f}$ is the final sample weight. For non-isothermal linear heating, $\beta=d T / d t$ and by substituting Equation (2) into Equation (3), the expression becomes Equation (5):

$$
\frac{d \alpha}{d T}=\frac{A}{\beta} \cdot \exp \left(\frac{-E_{a}}{R T}\right) \cdot f(\alpha)
$$

Rearranging Equation (5) and integrating within the limits of 0 to $T$ for temperature and 0 to $\alpha$ for conversion gives Equation (6):

$$
g(\alpha)=\int_{0}^{\alpha} \frac{d \alpha}{f(\alpha)}=\frac{A}{\beta} \int_{0}^{T} \exp \left(\frac{-E_{a}}{R T}\right) d T
$$

The temperature integral term of right side has no methodical solution and in order to simplify Equation (6), the term $-E_{a} / R T$ is replaced with $p(x)$, which gives Equation (7):

$$
g(\alpha)=\left(\frac{A E}{\beta R}\right) \cdot p(x)
$$

Thus, in the current study, the term $p(x)$ was proposed to be approximated using widelyused isoconversional model-free method, i.e. Kissinger-Akahira-Sunose (KAS) and modelfitting method, i.e. Coats-Redfern. For modelfree method, it is known to be efficient enough to handle the complexity of biomass decomposition reaction. Estimation on the temperature integral was based on linearization by Doyle's empirical approximation as shown in Equation (8) [11]:

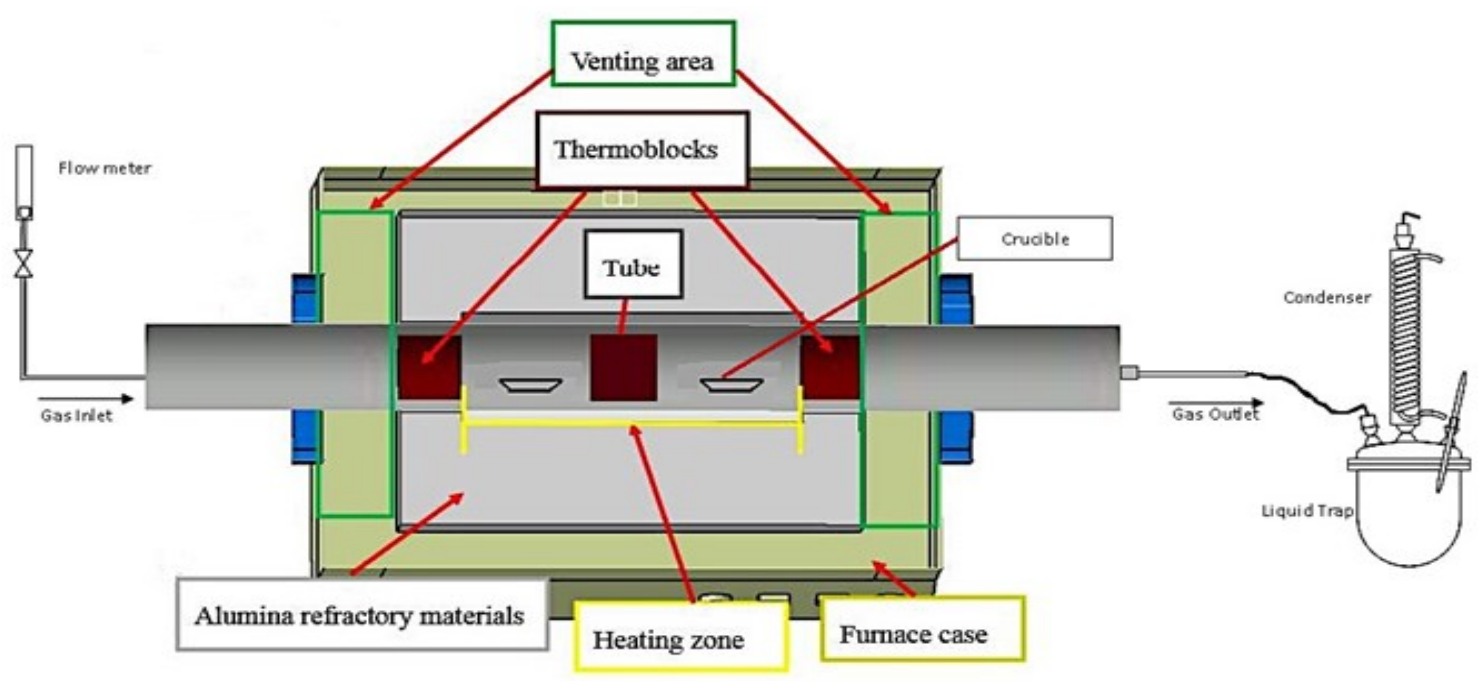

Figure 1. Torrefaction experimental set-up

Copyright ( $)$ 2020, BCREC, ISSN 1978-2993 


$$
\log p(x)=-2.315+0.4567 x
$$

The KAS equation which relates heating rate and inverse temperature can be expressed as the following Equation (9) [12,13]:

$$
\ln \left(\frac{\beta}{T^{2}}\right)=\ln \left(\frac{A E_{a}}{R g(\alpha)}\right)-\frac{E_{a}}{R T}
$$

At the progressing values of conversion, the slope of straight-line plot of $\ln \left(\beta / T^{2}\right)$ versus $1 / T$ allows activation energy to be determined. As for model-fitting kinetic method, Coats-Redfern (CF) is a widely-accepted method which uses the integral form of the non-isothermal rate law where approximation of the temperature integral produces the expression shown in Equation 10 [14]:

$$
\ln \left[\frac{g(\alpha)}{T^{2}}\right]=-\frac{E_{a}}{R T}+\ln \left(\frac{A R}{\beta E_{a}}\right)\left(1-\frac{2 R T}{E_{a}}\right)
$$

The above equation can be further simplified in accordance to customary values of $E_{a}(80-260$ $\mathrm{kJ} / \mathrm{mol}$ ) and by assuming $2 R T / E_{a}<<1$, the simplified form is expressed as in Equation 11 [15]:

$$
\ln \left[\frac{g(\alpha)}{T^{2}}\right]=-\frac{E_{a}}{R T}+\ln \left(\frac{A R}{\beta E_{a}}\right)
$$

A straight-line plot will enable apparent activation energy, reaction mechanism and preexponential factor to be determined from the slope and the intercept, respectively. Integral reaction mechanism $g(\alpha)$ indicating the reaction limiting step is chosen based on the best fit data with the highest correlation coefficient, $\mathrm{R}^{2}$.

\section{Results and Discussion}

3.1 Physico-chemical Characteristics and Thermal Decomposition Behaviors of Raw and Torrefied Biomass Pellets

Generally, for a raw biomass to be converted into fuel, the physico-chemical properties need to be studied. The aim is to determine its compatibility and initial properties in its original form, which compared to upgraded biomass fuel when subjected to torrefaction treatment. The characteristics of raw biomass helps in simplifying parameters selection in torrefaction process and thus, determines the best parameters critical in producing good quality biochar compatible for coal substitute. As shown in Table 1, both raw (ROPFP) and torrefied OPF (TOPFP) biomass pellets at temperatures $200{ }^{\circ} \mathrm{C}$ (TOPFP200), $250{ }^{\circ} \mathrm{C}$ (TOPFP250), 300 ${ }^{\circ} \mathrm{C}$ (TOPFP300), were examined to determine their potential as solid biochar. Moisture contents of both raw biomasses showed low values $(<3 \mathrm{wt} \%)$ due to open-drying activities prior to pelletization in addition to moisture being driven off during pelletization (die temperature approximately $70{ }^{\circ} \mathrm{C}$ ).

Figure 2(a) and (b) demonstrate the weight loss curves (TG) and differential thermogravimetric profiles, respectively, for both raw and torrefied pellets of OPF, respectively. For the

\begin{tabular}{|c|c|c|c|c|}
\hline & ROPFP & TOPFP200 & TOPFP250 & TOPFP300 \\
\hline \multicolumn{5}{|l|}{ Proximate Analysis } \\
\hline Moisture (wt\%, ar) & 1.89 & 4.61 & 1.79 & 1.40 \\
\hline Volatile matter (wt\%, ar) & 58.52 & 64.57 & 47.24 & 34.33 \\
\hline Fixed carbon $(w \mathrm{t} \%, a r)$ & 16.81 & 19.92 & 23.05 & 46.55 \\
\hline Ash (wt\%,ar) & 24.20 & 15.51 & 29.70 & 19.12 \\
\hline \multicolumn{5}{|l|}{ Ultimate Analysis (wt\%, ar) } \\
\hline $\mathrm{C}$ & 48.39 & 36.40 & 47.07 & 58.57 \\
\hline $\mathrm{H}$ & 7.27 & 4.90 & 5.48 & 4.78 \\
\hline $\mathrm{N}$ & 2.06 & 1.95 & 2.00 & 1.35 \\
\hline $\mathrm{S}$ & ND & ND & ND & ND \\
\hline O (by difference) & 42.28 & 56.75 & 45.45 & 35.30 \\
\hline $\mathrm{H} / \mathrm{C}$ ratio & 0.15 & 1.60 & 1.39 & 0.97 \\
\hline $\mathrm{O} / \mathrm{C}$ ratio & 0.87 & 1.17 & 0.72 & 0.45 \\
\hline$H H V(M J / k g, a r)$ & 17.09 & 18.94 & 20.80 & 25.43 \\
\hline $\begin{array}{l}\text { *ar-as received; ND-non-dete } \\
\text { method used) }\end{array}$ & (the su & content was & e detectio & f $0.02 \%$ of $t$ \\
\hline
\end{tabular}
purpose of clarity and decomposition evalua-

Table 1. Properties of raw (ROPFP) and torrefied (TOPFP) at respective torrefaction temperatures and 60 min holding time. 
tion between raw and torrefied products, only torrefied biomass samples with holding time 60 minutes were selected for discussion. At high torrefaction temperature, thermal decomposition between raw and torrefied samples displayed a clear difference, as more evidently shown in derivative thermogravimetric (DTG) profiles (Figure 2(b)).

For biomass samples torrefied at temperature $200{ }^{\circ} \mathrm{C}$, hemicellulose content still exists as shown by the existence of small/less apparent shoulder peak, which subsequently caused their thermal decomposition profiles followed that of raw samples. During light torrefaction temperature regime $\left(200-250^{\circ} \mathrm{C}\right)$, thermal degradation was mainly caused by moisture liberation and limited devolatilization of hemicellulose due to minor depolymerization reactions [16]. While for samples torrefied at temperature at $250^{\circ} \mathrm{C}$, characteristic peak / shoulder of hemicellulose disappeared indicating hemicellulose and light volatiles were successfully removed during torrefaction pretreatment. Hemicellulose degrades extensively at temperature $\geq$ $250{ }^{\circ} \mathrm{C}$ and reported to end at temperature approximately $280^{\circ} \mathrm{C}$ [17].

In terms of reactivity, based on the derivative mass loss profiles shown in Figure 2, biomass samples torrefied at $200{ }^{\circ} \mathrm{C}$ showed greater reactivity than its raw forms. This occurrence was further confirmed via proximate analyses data (Table 1) where volatile matter was found to increase as $T_{\text {torr }}$ of $200{ }^{\circ} \mathrm{C}$ then decrease as $T_{\text {torr }}$ further increased from $250{ }^{\circ} \mathrm{C}$ to $300{ }^{\circ} \mathrm{C}$. Uneven distribution of biomass macromolecules and possible interactions among the constituents that resulted in formation of new volatiles and possible overlapping decomposition of extractives might be the reasons for this

(a)

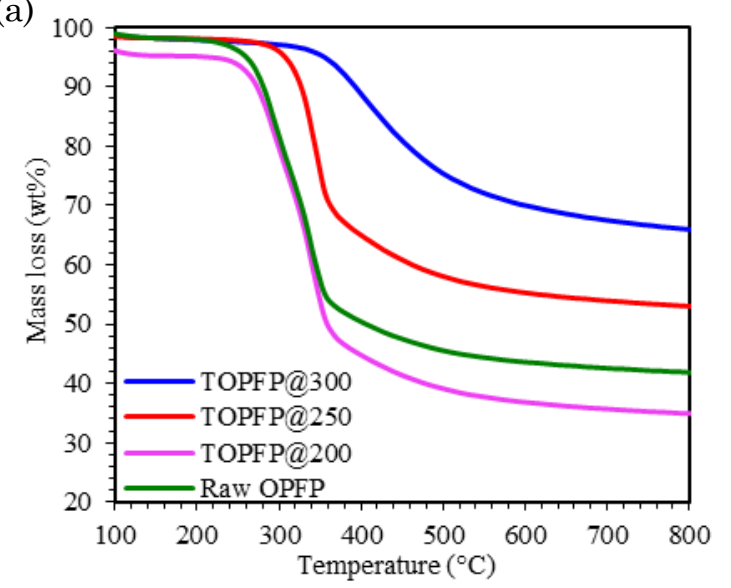

increase of volatile matter and then, released again as heating continues [18]. Halpern et al. [19] have also reported that between these temperatures, thermally unstable hemicellulose degradation occurred due to dehydration reactions which involved bond scissions that released $\mathrm{H}_{2} \mathrm{O}$, formation reactions of carbonyl and carboxyl groups accompanied by elimination of $\mathrm{CO}$ and $\mathrm{CO}_{2}$ and finally, limited devolatilization and carbonization which produces tars and chars.

DTG peak heights were observed to decrease as torrefaction temperature increased, and shifted to the right, indicating reduction in reactivity as more volatiles were driven off during torrefaction process. This also implies that cellulose and lignin started to decompose with limited carbonization, thus significantly reduced the volatiles of torrefied samples resulting in less reactive product. Peaks representing these two components were more noticeable at temperature above $300{ }^{\circ} \mathrm{C}$, in which according to Yang et al. [20], thermal degradation temperature ranges for cellulose and lignin were 315-400 ${ }^{\circ} \mathrm{C}$ and $160-900{ }^{\circ} \mathrm{C}$, respectively. Trends of TG and DTG profiles in this study are in agreement with previous researches [2123]. In order to further verify the proposition that torrefied biomass products having similar properties with sub-bituminous coals, DTG profiles of Malaysian sub-bituminous coal (Silantek) were also added in Figure 2(b). Interestingly, torrefied biomass at highest $T_{\text {torr }}$ demonstrates similar profiles as Silantek coal, albeit their maximum peak temperatures were earlier than coal's. According to Chen and Kuo [24], during torrefaction temperature range, significant decomposition of hemicellulose and partial cellulose occurred at $290^{\circ} \mathrm{C}$, resulting

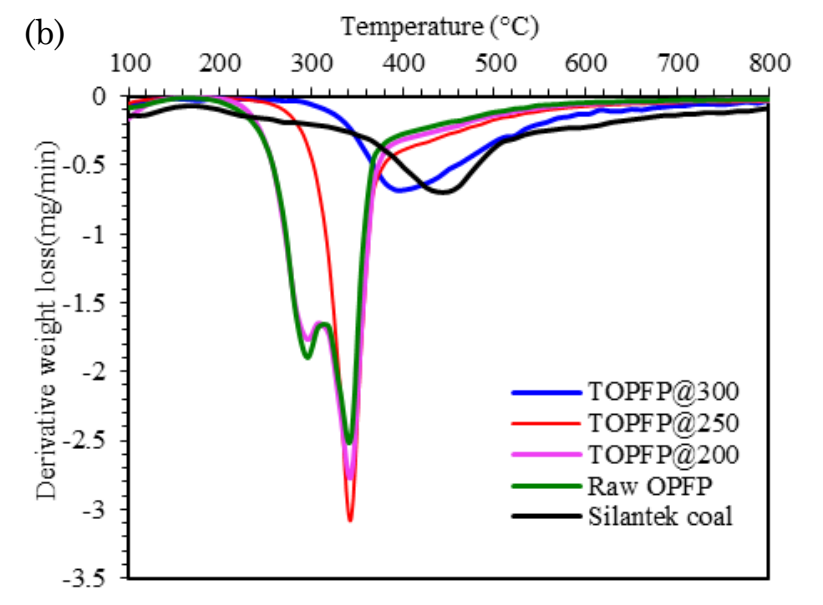

Figure 2. (a) TG and (b) DTG curves of raw and torrefied OPFP at holding time 60 min 
in carbon-rich solid char with coal-like properties.

\subsection{Raw OPFP Torrefaction Kinetics}

\subsubsection{Model-free kinetic evaluation via KAS method}

Model-free method is based on the assumption that when activation energy value is constant, the rate of reaction is a function of only temperature [25]. Experimental data with four heating rates $\left(5,10,15\right.$, and $\left.20^{\circ} \mathrm{C} / \mathrm{min}\right)$ for temperature range $105^{\circ} \mathrm{C}$ up to $400{ }^{\circ} \mathrm{C}$ obtained from thermogravimetric analysis were fitted according to the chosen model-free method. i.e. KAS, in order to calculate the apparent activation energy $\left(E_{a}\right)$ and their corresponding correlation coefficients, $\mathrm{R}^{2}$. It should be noted that, as aforementioned, the drying stage was not included in the torrefaction kinetic analysis as at temperatures less than $105^{\circ} \mathrm{C}$ only moisture and physically absorbed water was removed [26]. Thus, the analysis of KAS model applied was intentionally limited to torrefaction process with lower temperature set at $105^{\circ} \mathrm{C}$ and extended upper temperature limit set at 400 ${ }^{\circ} \mathrm{C}$. For ease of kinetic analysis interpretation, degradation region of raw biomass under study has been based on temperature range proposed by Yang et al. [27], which are; $220-315{ }^{\circ} \mathrm{C}$ (dominant hemicellulose degradation stage) and $315-400{ }^{\circ} \mathrm{C}$ (cellulose degradation stage). Thus, the decompositions involved during torrefaction has been henceforth referred to as Stage 1 and Stage 2, respectively, rather than by lignocellulosic composition. The reason is with regard to the selected temperature range $\left(105-400^{\circ} \mathrm{C}\right)$ for the torrefaction kinetic analy- sis, and taking into account the complexities involved in biomass decomposition, cellulose, hemicellulose and lignin decompositions that might occur simultaneously.

For the current study, integral equation of KAS method (Equation (9)) was applied where the slope of straight line of $\ln \left(\beta / T^{2}\right)$ against $1 / T$ was plotted in Figure 3(a), which then allows $E_{a}$ to be determined. Tabulated values of $E_{a}$ at different conversions and corresponding correlation coefficients $\left(\mathrm{R}^{2}\right)$ are shown in Table 2 and displayed in Figure 3(b) of intervals 0.05. It should be noted that the end value of conversion degree $(\alpha)$ in these analyses ended at 0.90 where calculated $E_{a}$ values for all raw samples using each method displayed sudden increase at $\alpha=0.95$. This rise is possibly due to the sole lignin decomposition where lignin needs higher chemical bond-breaking energy to decompose due to its aromatic chemical structures. This is further confirmed by observing the DTG thermal profile (Figure 2(b)) where cellulose decompositions in raw OPFP ended at around 356$382{ }^{\circ} \mathrm{C}$, depending on individual heating rates. Thus, beyond these temperatures, lignin decomposition is believed to be significant and since lignin is mainly consists of aliphatic and aromatic structures, higher thermal energy is needed to overcome its minimum energy barrier (higher $E_{a}$ ), thus the sudden surge in activation energy values at $\alpha=0.95$.

Average $E_{a}$ values are noticeably high in ROPFP (239-251 kJ/mol) in which, based on the literatures on various agricultural residues kinetic studies, $E_{a}$ calculated for various types of biomass are as follows; rice straw (140-267 $\mathrm{kJ} / \mathrm{mol}$ ) [26], rice husk (168 kJ/mol) [28], olive pomace (162-602 kJ/mol) [29], bagasse (169 (a)

$1000 / \mathrm{T}(1 / \mathrm{K})$

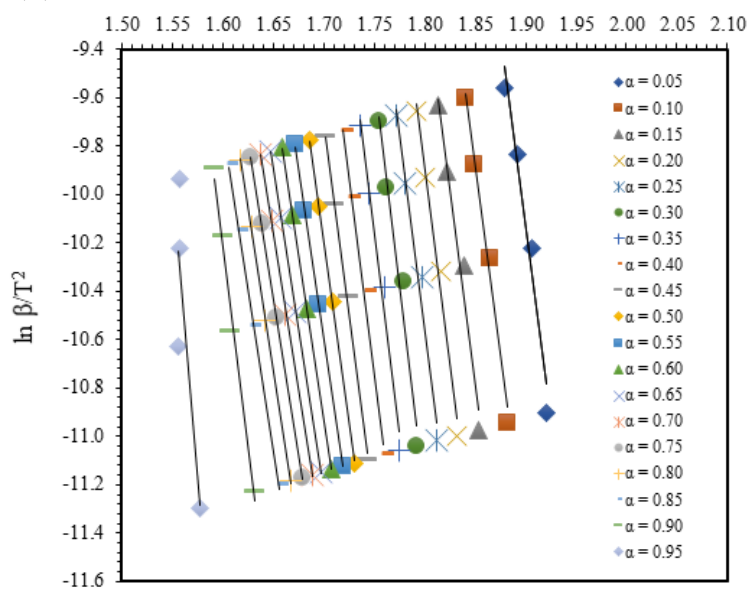

(b)

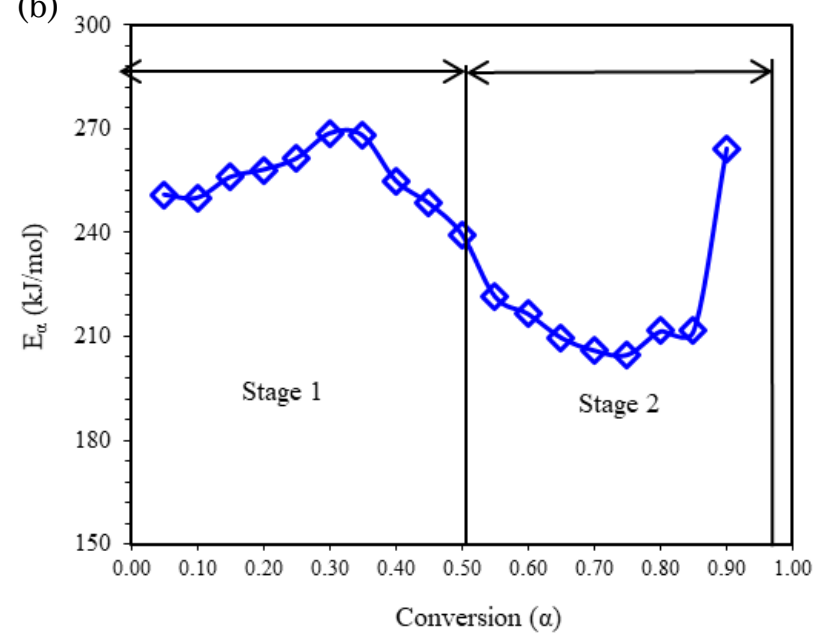

Figure 3. (a) KAS plots and (b) activation energy for ROPFP at different values of conversion 
$\mathrm{kJ} / \mathrm{mol}$ ) [28], and olive tree pruning (151-209 $\mathrm{kJ} / \mathrm{mol}$ ) [30]. Whereas, from previous studies on woody biomass of different categories (softwood/hardwood) showed lower $E_{a}$ values via various non-isothermal kinetic methods, for example; ashwood-hardwood (133-167 kJ/mol) [31], poplar wood (159 kJ/mol) [32], Ahun wood $(127 \mathrm{~kJ} / \mathrm{mol})$ and Araba wood $(125 \mathrm{~kJ} / \mathrm{mol})$ [33]. Therefore, from this comparison, it can be inferred that agricultural biomass, such as: raw OPFP, showed higher $E_{a}$ values of 239.03 $\mathrm{kJ} / \mathrm{mol}$ (Table 3), as compared to woody biomass, which is agreeable to the current results obtained. An increase of $E_{a}$ values during Stage 1 was also expected where according to Grigiante et al. [31], this is due to the random scission of linear chain in hemicellulose which led to the rise in $E_{a}$ values as the thermal heating progressed. The crosslinking behavior and its effects on the numerously branched polymeric structure of hemicellulose and extractives constituents that yet to be degraded, gave rise to the $E_{a}$ values upon thermal heating. In the case of ROPFP, as $\alpha$ reached 0.35 and above, a decreasing trend of $E_{a}$ values was observed in which the earlier stage of decomposition might not follow the abovementioned explanations. This suggests almost complete degradation of hemicellulose occurred at average temperature of $297^{\circ} \mathrm{C}$, typically described as the end temperature of hemicellulose degradation from literatures [34]. The efficacy of linear fitting for the experimental data obtained via TGA into KAS methods were assessed via correlation coefficients $\left(\mathrm{R}^{2}\right)$ as listed in Table 2 with obtained good fitting of data where $\mathrm{R}^{2}$ obtained was more than $98 \%$.

\subsubsection{Model-fitting kinetic evaluation via Coats-Redfern (CR) method}

Model-fitting kinetic method applied in this study, Coats-Redfern (CR) enabled the determination of the complete kinetic triplets i.e. activation energy, reaction mechanism $(g(\alpha))$ and pre-exponential factor $(A)$. Based on the highest correlation coefficients obtained from these plots, Table 4 lists the summary of the kinetic parameters attained via CR method for raw OPFP at respective heating rates as well as decomposition stages. Figure 4 displays the plot of $\left[g(\alpha) / T^{2}\right]$ against $1 / T$ for the overall torrefac-

Table 3. Summary of ROPFP torrefaction kinetics via KAS method

\begin{tabular}{cccc}
\hline $\begin{array}{c}\text { Summary of } \\
\text { ROPFP de- } \\
\text { composition }\end{array}$ & $\begin{array}{c}\text { Conversion } \\
\text { range }\end{array}$ & $\begin{array}{c}E_{a} \\
(\mathrm{~kJ} / \mathrm{mol})\end{array}$ & $\mathrm{R}^{2}$ \\
\hline Overall & $0.05<\alpha<0.90$ & 239.03 & 0.987 \\
Stage 1 & $0.05<\alpha<0.50$ & 255.64 & 0.980 \\
Stage 2 & $0.55<\alpha<0.90$ & 218.28 & 0.997 \\
\hline
\end{tabular}

Table 2. Kinetic parameters determination using KAS method

\begin{tabular}{ccccc}
\hline Average $\mathrm{T}\left({ }^{\circ} \mathrm{C}\right)$ & Decomposition stage & Conversion, $\alpha$ & $E_{a}(\mathrm{~kJ} / \mathrm{mol})$ & $\mathrm{R}^{2}$ \\
\hline 253.39 & & 0.05 & 251.00 & 0.955 \\
264.83 & 0.10 & 250.09 & 0.983 \\
272.83 & 0.15 & 256.07 & 0.974 \\
279.41 & Stage 1 (dominated by & 0.20 & 258.17 & 0.979 \\
285.43 & hemicellulose degra- & 0.25 & 261.44 & 0.977 \\
291.16 & dation) & 0.30 & 268.66 & 0.970 \\
296.97 & & 0.35 & 268.00 & 0.976 \\
302.69 & 0.40 & 255.00 & 0.989 \\
308.22 & & 0.45 & 248.50 & 0.994 \\
313.36 & & 0.50 & 239.49 & 0.999 \\
\hline 318.21 & & 0.55 & 221.56 & 1.000 \\
322.13 & 0.60 & 216.59 & 1.000 \\
326.16 & & 0.65 & 209.73 & 1.000 \\
329.63 & & 0.70 & 206.04 & 0.999 \\
333.14 & Stage 2 (dominated by & 0.75 & 204.83 & 0.999 \\
336.98 & cellulose degradation) & 0.80 & 211.57 & 0.998 \\
341.68 & & 0.85 & 211.66 & 0.996 \\
348.94 & & 0.90 & 264.24 & 0.983 \\
367.13 & & 0.95 & 403.68 & 0.749 \\
\hline
\end{tabular}


tion temperature range at heating rate 10 ${ }^{\circ} \mathrm{C} / \mathrm{min}$ for various reaction mechanisms (reaction order (F1-F7), diffusion (D1-D4), geometrical contraction (R1-R3), power law (P2-
P4) and nucleation models (A2-A4)) along with the stages involved during torrefaction for raw OPFP. As shown in Table 4, Stage 1, which is mainly associated with light volatiles decompo-
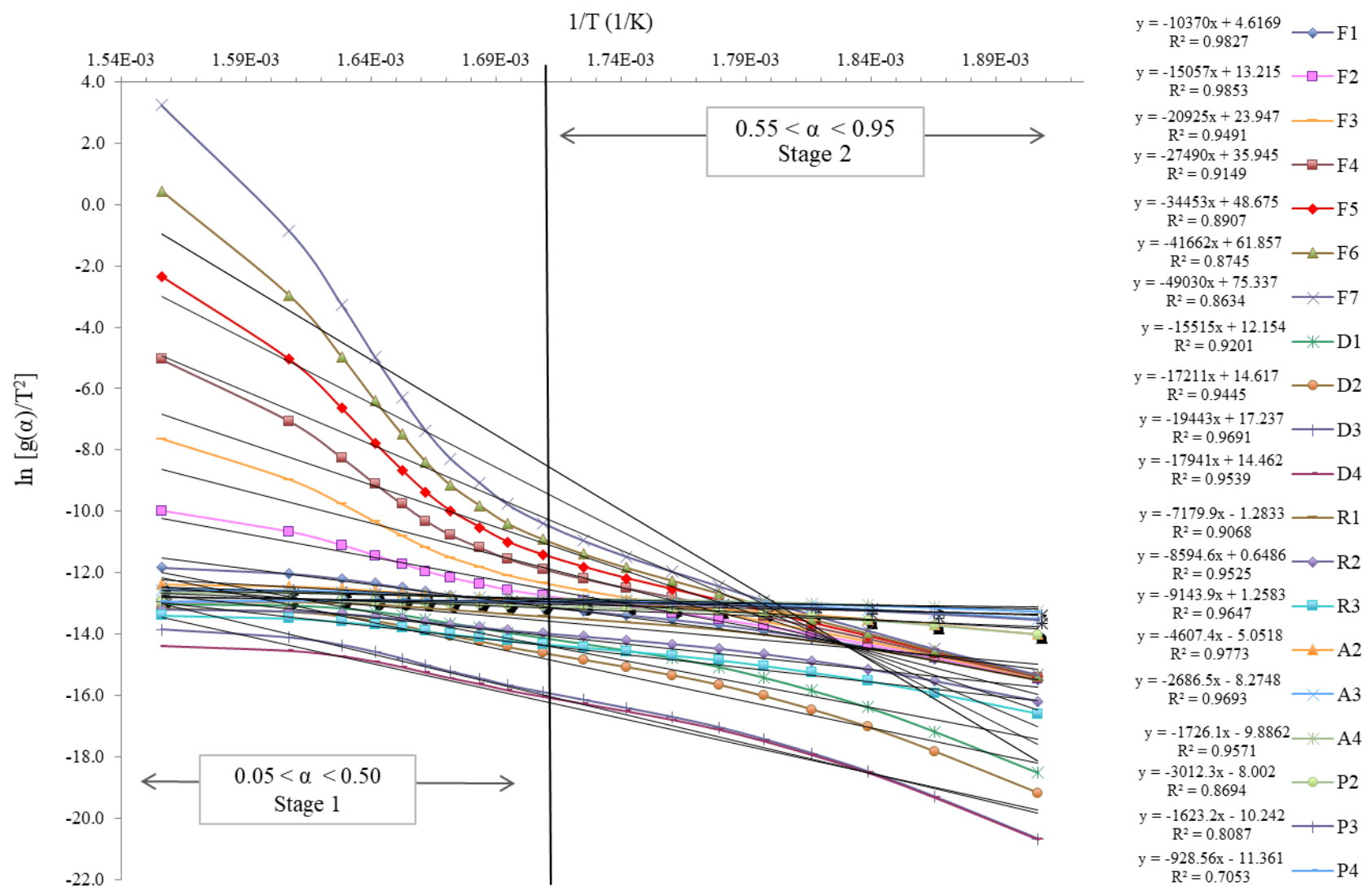

Figure 4. Coats-Redfern plot for raw OPFP at different values of conversion

Table 4. Kinetic parameters determination using Coats-Redfern method

\begin{tabular}{|c|c|c|c|c|c|}
\hline $\begin{array}{c}\text { Heating rate } \\
\left({ }^{\circ} \mathrm{C} / \mathrm{min}\right)\end{array}$ & $\alpha$ range & Mechanistic model & $E_{a}(\mathrm{~kJ} / \mathrm{mol})$ & $A\left(\min ^{-1}\right)$ & $\mathrm{R}^{2}$ \\
\hline \multicolumn{6}{|l|}{ Stage 1} \\
\hline 5 & $0.05<\alpha<0.60$ & F3 & 136.13 & $7.75 \times 10^{11}$ & 0.997 \\
\hline 10 & $0.05<\alpha<0.50$ & $\mathrm{~F} 4$ & 146.35 & $1.39 \times 10^{13}$ & 1.000 \\
\hline 15 & $0.05<\alpha<0.45$ & $\mathrm{~F} 4$ & 146.14 & $1.46 \times 10^{13}$ & 1.000 \\
\hline 20 & $0.05<\alpha<0.45$ & F5 & 167.25 & $2.10 \times 10^{15}$ & 1.000 \\
\hline Average & $0.05<\alpha<0.50$ & F3-F5 & 148.97 & $5.32 \times 10^{14}$ & 0.999 \\
\hline \multicolumn{6}{|l|}{ Stage 2} \\
\hline 5 & $0.65<\alpha<0.95$ & F7 & 807.32 & $6.99 \times 10^{73}$ & 0.986 \\
\hline 10 & $0.55<\alpha<0.95$ & $\mathrm{~F} 4$ & 413.05 & $1.46 \times 10^{37}$ & 0.992 \\
\hline 15 & $0.50<\alpha<0.95$ & $\mathrm{~F} 2$ & 179.73 & $6.72 \times 10^{15}$ & 0.990 \\
\hline 20 & $0.50<\alpha<0.95$ & F1 & 90.01 & $3.56 \times 10^{7}$ & 0.987 \\
\hline Average & $0.55<\alpha<0.95$ & F1-F7 & 227.60 & $4.85 \times 10^{36}$ & 0.990 \\
\hline \multicolumn{6}{|l|}{ Overall } \\
\hline 5 & \multirow{4}{*}{$0.05<\alpha<0.95$} & $\mathrm{~F} 2$ & 131.95 & $2.49 \times 10^{11}$ & 0.988 \\
\hline 10 & & $\mathrm{~F} 2$ & 125.19 & $8.26 \times 10^{10}$ & 0.985 \\
\hline 15 & & $\mathrm{~F} 1$ & 89.75 & $2.89 \times 10^{7}$ & 0.989 \\
\hline 20 & & $\mathrm{~F} 1$ & 90.24 & $3.85 \times 10^{7}$ & 0.988 \\
\hline & Average & $\mathrm{F} 1-\mathrm{F} 2$ & 109.28 & $8.28 \times 10^{10}$ & 0.987 \\
\hline
\end{tabular}

Note: F - Reaction order mechanism 
sition in hemicellulose and extractives, raw OPFP followed reaction-order mechanism with $n \geq 3$ whereby as heating rate was increased, reaction order also increased which indicates higher reaction rate, i.e. reactivity. As for stage 2 , which is mainly associated to cellulose decomposition, raw OPFP similarly followed reaction order mechanism but $n^{\text {th }}$ order decreased with increase of heating rate.

Expectedly, for overall torrefaction temperature range, reaction mechanism for raw OPFP followed reaction order mechanism, i.e. first reaction order $(n=1)$ indicated as F1 with good correlation coefficients $\left(R^{2}\right)$ obtained in all stages, with $R^{2}$ values of 0.985 to 1 . In addition, the average activation energy obtained during the overall temperature range was low at 109.28 $\mathrm{kJ} / \mathrm{kg}$ that suggest easier start of decomposition stage. However, it should also be noted that for ROPFP at HR5 and HR10, values of activation energies are unexpectedly high and followed $2^{\text {nd }}$ order reaction mechanisms (F2), which suggest the existence of more complex reaction involved at these heating rates, as suggested by few researchers $[33,35,36]$. In comparison to apparent activation energies obtained via $\mathrm{C}-\mathrm{R}$ and $\mathrm{KAS}$ methods, it was observed that the overall $E_{a}$ values for $\mathrm{C}-\mathrm{R}$ method is much lower by more than This observation might be caused by an assumption of isoconversional method, such as: KAS method which disregards any reaction mechanism to calculate kinetic parameters, whereas model-fitting method determine kinetic parameters using a mass dependent function [36-38].

\section{Conclusions}

Physico-chemical analyses and thermal behavior of raw and torrefied oil palm frond pellets prepared at different torrefaction temperatures have been studied. Improvements on the properties were achieved via torrefaction treatment where high heating values, fixed carbon and elemental carbon contents significantly increased. The properties are desirable for treated biomass to be used as a potential bioenergy feedstock. Thermal degradation behavior via TGA showed hemicellulose was removed thus producing torrefied biomass nearing the decomposition behavior of coal. Via dynamic kinetic analysis, the variation of activation energies was obtained between the two methods applied (KAS and C-R methods) in which CoatsRedfern method is deemed to be a more reliable method to determine the kinetic parameters where from this study. It was found that thermal decomposition of raw OPFP follows reaction order mechanism.

\section{Acknowledgment}

The authors gratefully acknowledge the support received from Research Management Centre (RMC) and Faculty of Chemical Engineering, Universiti Teknologi MARA, Shah Alam, Selangor, Malaysia.

\section{References}

[1] Energy Commission (Malaysia), Energy in Malaysia: 2017, Energy Commission, vol. 12, Putrajaya.

[2] Ozturk, M., Saba, N., Altay, V., Iqbal, R., Hakeem, K.R., Ibrahim, F.H. (2017). Biomass and bioenergy: An overview of the development potential in Turkey and Malaysia. Renew. Sustain. Energy Rev., 79, 1285-1302. DOI: 10.1016/j.rser.2017.05.111.

[3] Energy Commission (Malaysia), (2017). Peninsular Malaysia Electricity Supply Outlook 2017. Putrajaya, Malaysia.

[4] Nhuchhen, D., Basu, P., Acharya, B. (2014). A Comprehensive Review on Biomass Torrefaction. Int. J. Renew. Energy Biofuels, 2014, 156. DOI: $10.5171 / 2014.506376$.

[5] Medic, D., Darr, M., Shah, A., Potter, B., Zimmerman, J. (2012). Effects of torrefaction process parameters on biomass feedstock upgrading. Fuel, 91(1), 147-154. DOI: 10.1016/j.fuel.2011.07.019.

[6] Zannikos, F., Kalligeros, S., Anastopoulos, G., Lois, E. (2013). Converting biomass and waste plastic to solid fuel rriquettes. J. Renew. Energy, 2013, 1-9. DOI: $10.1155 / 2013 / 360368$.

[7] Loh, S.K. (2017). The potential of the Malaysian oil palm biomass as a renewable energy source. Energy Convers. Manag., 141, 285298. DOI: 10.1016/j.enconman.2016.08.081.

[8] Brachi, P., Miccio, F., Ruoppolo, G. (2015). Isoconversional kinetic analysis of olive pomace decomposition under torrefaction operating conditions. Fuel Process. Technol., 130, 147-154. DOI: 10.1016/j.fuproc.2014.09.043.

[9] Chen, W.-H., Wu, Z.-Y., Chang, J.-S. (2014). Isothermal and non-isothermal torrefaction characteristics and kinetics of microalga Scenedesmus obliquus CNW-N. Bioresour. Technol., 155, 245-251. DOI: 10.1016/j.biortech.2013.12.116.

[10] Doddapaneni, T.R.K.C., Konttinen, J., Hukka, T.I., Moilanen, A. (2016). Influence of torrefaction pretreatment on the pyrolysis of $\mathrm{Eu}$ calyptus clone: A study on kinetics, reaction mechanism and heat flow. Ind. Crops Prod., 92, 244-254. DOI: 10.1016/j.indcrop.2016.08.013. 
[11] Doyle, C.D. (1965). Series Approximations to the Equation of Thermogravimetric Data. Nature, 207, 290-291. DOI: 10.1038/207290a0

[12] Akahira, T., Sunose, T. (1971). Method of determining activation deterioration constant of electrical insulating materials. Res. Rep. Chiba Inst. Technol. (Sci. Technol.), 16, 22-31.

[13] Kissinger, H.E. (1957). Reaction Kinetics in Differential Themal Analysis. Anal. Chem., 29(11), 1702-1706. DOI: 10.1021/ac60131a045.

[14] Coats, A.W., Redfern, J.P. (1964). Kinetic Parameters from Thermogravimetric Data. $\mathrm{Na}$ ture, 201, 68-69. DOI: 10.1038/201068a0.

[15] White, J.E., Catallo, W.J., Legendre, B.L. (2011). Biomass pyrolysis kinetics: A comparative critical review with relevant agricultural residue case studies. J. Anal. Appl. Pyrolysis, 91(1), 1-33, DOI: 10.1016/j.jaap.2011.01.004.

[16] Medic, D. (2012). Investigation of torrefaction process parameters and characterization of torrefied biomass. PhD Dissertation, Iowa State University.

[17] Chang, S., Zhao, Z., Zheng, A., He, F., Huang, Z., Li, H. (2012). Characterization of products from torrefaction of sprucewood and bagasse in an auger reactor. Energy \& Fuels, 26(11), 7009-7017, DOI: 10.1021/ef301048a.

[18] Haykiri-Acma, H., Yaman, S, Kucukbayrak, S. (2017). Effects of torrefaction on lignin-rich biomass (hazelnut shell): Structural variations. J. Renew. Sustain. Energy, 9(063102), 1-10, DOI: 10.1063/1.4997824.

[19] Halpern, Y., Patai, S. (1969). Pyrolytic Reactions of Carbohydrates. Part VII. Simultaneous DTA-TGA Study of the Thermal Decomposition of Cellulose In Vacuo. Isr. J. Chem., 7(5), 691-696. DOI: 10.1002/ijch.196900090.

[20] Yang, H., Yan, R., Chen, H., Lee, D. H., Zheng, C. (2007). Characteristics of hemicellulose, cellulose and lignin pyrolysis. Fuel, 86 ( 12 ), $\quad 1781-1788$. D O I : 10.1016/j.fuel.2006.12.013.

[21] Kim, Y.-H., Lee, S.-M., Lee, H.-W., Lee, J.-W. (2012). Physical and chemical characteristics of products from the torrefaction of yellow poplar (Liriodendron tulipifera). Bioresour. Technol., 116, 120-125. DOI: 10.1016/j.biortech.2012.04.033.

[22] Tran, K.-Q., Luo, X., Seisenbaeva, G., Jirjis, R. (2013). Stump torrefaction for bioenergy application. Appl. Energy, 112, 539-546, DOI: 10.1016/j.apenergy.2012.12.053.

[23] Wannapeera, J., Fungtammasan, B., Worasuwannarak, N. (2011). Effects of temperature and holding time during torrefaction on the pyrolysis behaviors of woody biomass. J. Anal. Appl. Pyrolysis, 92(1), 99-105. DOI: 10.1016/j.jaap.2011.04.010.
[24] Chen, W.-H., Kuo, P.-C. (2011). Torrefaction and co-torrefaction characterization of hemicellulose, cellulose and lignin as well as torrefaction of some basic constituents in biomass. Energy, 36(2), 803-811. DOI: 10.1016/j.energy.2010.12.036.

[25] Dhyani, V., Bhaskar, T. (2018). A comprehensive review on the pyrolysis of lignocellulosic biomass. Renew. Energy, 129, 695-716. DOI: 10.1016/j.renene.2017.04.035.

[26] Mishra, G., Bhaskar, T. (2014). Non isothermal model free kinetics for pyrolysis of rice straw. Bioresour. Technol., 169, 614-621. DOI: 10.1016/j.biortech.2014.07.045.

[27] Yang, H., Yan, R., Chen, H., Lee, D.H., Zheng, C. (2007). Characteristics of hemicellulose, cellulose and lignin pyrolysis. Fuel, 86(12-13), $1781-1788$. D O I : 10.1016/j.fuel.2006.12.013.

[28] Yao, F., Wu, Q., Lei, Y., Guo, W., Xu, Y. (2008). Thermal decomposition kinetics of natural fibers: Activation energy with dynamic thermogravimetric analysis. Polym. Degrad. Stab., 93(1), 90-98. DOI: 10.1016/j.polymdegradstab.2007.10.012.

[29] Brachi, P., Miccio, F., Miccio, M., Ruoppolo, G. (2015). Isoconversional kinetic analysis of olive pomace decomposition under torrefaction operating conditions. Fuel Process. Technol., $130(\mathrm{C}), \quad 147-154$. DOI : 10.1016/j.fuproc.2014.09.043.

[30] Martín-Lara, M.A., Blázquez, G., Zamora, M.C., Calero, M. (2017). Kinetic modelling of torrefaction of olive tree pruning. Appl. Therm. Eng., 113, 1410-1418. DOI: 10.1016/j.applthermaleng.2016.11.147.

[31] Grigiante, M., Brighenti, M., Antolini, D. (2016). A generalized activation energy equation for torrefaction of hardwood biomasses based on isoconversional methods. Renew. Energy, 99, 1318-1326. DOI: 10.1016/j.renene.2016.07.054.

[32] Slopiecka, K., Bartocci, P., Fantozzi, F. (2012). Thermogravimetric analysis and kinetic study of poplar wood pyrolysis. Appl. Energy, 97, 491-497. D O I: 10.1016/j.apenergy.2011.12.056.

[33] Oluoti, K., Doddapaneni, T.R.K.C., Richards, T. (2018). Investigating the kinetics and biofuel properties of Alstonia congensis and Ceiba pentandra via torrefaction. Energy, 150, 134-141. DOI: 10.1016/j.energy.2018.02.086.

[34] Chen, D., Gao, A., Cen, K., Zhang, J., Cao, X., $\mathrm{Ma}, \mathrm{Z}$. (2018). Investigation of biomass torrefaction based on three major components: Hemicellulose, cellulose, and lignin. Energy Convers. Manag., 169, 228-237. DOI: 10.1016/j.enconman.2018.05.063. 
[35] Burnham, A.K., Dinh, L.N. (2007). A comparison of isoconversional and model-fitting approaches to kinetic parameter estimation and application predictions. J. Therm. Anal. Calorim., 89(2), 479-490. DOI: 10.1007/s10973-0068486-1.

[36] Martí-Rosselló, T., Li, J., Leo, L. (2016). Kinetic models for biomass pyrolysis. Arch Ind Biotechnol, 1(1), 4-7.
[37] Vyazovkin, S. (2015). Some Basics En Route to Isoconversional Methodology in Isoconversional Kinetics of Thermally Stimulated Processes, Springer International Publishing Switzerland, 1-25.

[38] Šimon, P. (2004). Isoconversional methods: Fundamentals, meaning and application. $J$. Therm. Anal. Calorim., 76(1), 123-132. DOI: 10.1023/B:JTAN.0000027811.80036.6c. 2019 and Peer-Reviewers of Bulletin of Chemical Reaction Engineering \& Catalysis. 